\title{
Georges Schéhadé, Le Théâtre du poète. Correspondances dramatiques et dossier de réception
}

\section{Michela Colombo}

\section{(2) OpenEdition}

1 Journals

\section{Edizione digitale}

URL: https://journals.openedition.org/studifrancesi/3213

DOI: 10.4000/studifrancesi.3213

ISSN: 2421-5856

\section{Editore}

Rosenberg \& Sellier

\section{Edizione cartacea}

Data di pubblicazione: 1 juillet 2013

Paginazione: $487-488$

ISSN: 0039-2944

\section{Notizia bibliografica digitale}

Michela Colombo, «Georges Schéhadé, Le Théâtre du poète. Correspondances dramatiques et dossier de réception», Studi Francesi [Online], 170 (LVII | II) | 2013, online dal 30 novembre 2015, consultato il 02 février 2023. URL: http://journals.openedition.org/studifrancesi/3213 ; DOI: https://doi.org/10.4000/ studifrancesi.3213

\section{Questo documento è stato generato automaticamente il 2 février 2023.}

\section{(c) 9 (1) $\Theta$}

Creative Commons - Attribuzione - Non commerciale - Non opere derivate 4.0 Internazionale - CC BYNC-ND 4.0

https://creativecommons.org/licenses/by-nc-nd/4.0/ 


\title{
Georges Schéhadé, Le Théâtre du poète. Correspondances dramatiques et dossier de réception
}

\author{
Michela Colombo
}

\section{NOTIZIA}

GEORGES SCHÉHADÉ, Le Théâtre du poète. Correspondances dramatiques et dossier de réception, textes présentés et annotés par David MARTENS, préface de Robert ABIRACHED, Paris, Champion, 2012, pp. 528.

1 L'opera drammaturgica di Georges Schehadé può essere annoverata fra le più celebri del Nouveau Théâtre. Pur essendo composta soltanto da sei pièces e da una pantomima, è caratterizzata da una voce poetica unica nel coevo panorama teatrale. Il volume in questione intende esaminare le caratteristiche di tale creazione e tracciare il percorso della sua ricezione critica in Francia. In tale prospettiva sono qui pubblicate per la prima volta integralmente le principali corrispondenze dell'autore de La Soirée des proverbes, insieme a una scelta di articoli che attestano la ricezione spesso movimentata delle pièces di Schehadé in Francia.

2 La relativa disaffezione di cui ha sofferto l'opera teatrale di Schehadé si è fatta sentire in Francia fin dall'inizio degli anni Settanta, nonostante il suo ingresso nel repertorio della Comédie-Française con la creazione de L'Émigré de Brisbane, ultima pièce dell'autore. Tale perdita di notorietà coincide con la fine di una produzione drammaturgica che ci si ripropone con tale volume di riscoprire. A questo scopo, David Martens cerca di far rivivere l'evento rappresentato dalla comparsa del teatro di Schehadé sulle scene francesi all'inizio degli anni Cinquanta e fino alla fine degli anni Sessanta. Per meglio rispondere a tale ambizione, l'opera consta di due parti complementari, che presentano un quadro dell'elaborazione e della ricezione delle diverse pièces. Il lettore scoprirà pertanto i retroscena della loro creazione, delle messe 
in scena e il modo in cui queste sono state accolte, attraverso l'interazione di diverse voci (l'autore, i registi, i critici) e di due tipologie di testi. La prima parte del volume presenta infatti una serie di corrispondenze del drammaturgo con tre dei registi delle sue pièces in Francia, ossia Georges Vitaly, Jean-Louis Barrault, Roland Monod, e anche con due dei suoi principali critici, Guy Dumur e Jacques Lemarchand, gli unici ad aver reso conto in maniera costante delle messe in scena in francese delle opere di Schehadé. Sono inoltre state aggiunte a questa raccolta alcune lettere molto interessanti scambiate da Schehadé con altri tre drammaturghi e poeti a lui contemporanei: Arthur Adamov, Andrée Chedid e Jean Tardieu. La seconda parte del volume presenta invece un dossier critico nel quale sono stati raccolti testi relativi alle messe in scena delle sei pièces di Schehadé in Francia fra il 1951 e il 1967. Compaiono sia i testi inseriti nei programmi, alcuni firmati dall'autore stesso, sia testi apparsi sulla stampa o nei «Cahiers de la Compagnie Renaud-Barrault». Segue poi una selezione di articoli tratti da un insieme di pubblicazioni rappresentative del panorama della critica drammaturgica parigina dell'epoca. La maggior parte di questi testi sono stati qui ripubblicati per la prima volta.

Presentando un materiale che permette di ricostruire più di quindici anni di creazione teatrale, questa edizione consente di ripercorrere l'avventura di Schehadé in Francia, dalla piccola sala del Théâtre de la Huchette (Monsieur Bob'le, 1951) fino alla ComédieFrançaise (L'Émigré de Brisbane, 1967), e costituisce così un invito alla lettura dell'opera drammaturgica di un autore che può essere a buon titolo definito come la principale figura della modernità letteraria libanese del xx secolo. 